\title{
Investigating the Relationship between Theory of Mind Ability and Academic Achievement and Self-Efficiency of Students with Conduct Disorder in Ardabil
}

\author{
Soheila Imanparvar ${ }^{1} \&$ Ali Khademi ${ }^{2}$ \\ 1 Department of Educational Psychology, Ajabshir Branch, Islamic Azad University, Ajabshir, Iran \\ ${ }^{2}$ Department of Psychology, Urmia Branch, Islamic Azad University, Urmia, Iran \\ Correspondence: Ali Khademi, Department of Psychology, Urmia Branch, Islamic Azad University, Urmia, Iran. \\ E-mail: soheila.e1361@gmail.com/Dr_ali_khademi@yahoo.com
}

Received: July 8, 2016

Accepted: July 8, 2016

Online Published: August 17, 2016

doi:10.5539/mas.v10n11p167

URL: http://dx.doi.org/10.5539/mas.v10n11p167

\begin{abstract}
The aim of this study was to determine the relationship between theory of mind ability and academic achievement and self-efficacy of students with conduct disorder in Ardabil. This descriptive study is correlational type, and the population of study consisted of all students with conduct disorder in high schools (secondary levels of 7, 8,9) of Ardabil in March, 2015. Multi-stage cluster sampling method was used which covered 384 person and then Rutter's behavioral disorders questionnaire form B was put at the disposal of teachers, and among people who were diagnosed with conduct disorder a total of 60 students with conduct disorder were selected as the sample group. Data were collected by the use of a questionnaire regarding self-efficiency in children and adolescents, Hopi's theory of mind, behavioral disorder questionnaire by Rutter form B and academic records. Obtained information was analyzed by using Pearson correlation coefficient test and regression test. The results showed that there is a significant relationship between theory of mind with academic achievement, self-efficiency, social self-efficiency, academic self-efficiency and emotional self-efficacy $(05 / 0>p)$. Regression analysis showed that theory of mind can predict significantly about $38 \%$ of the variances of academic achievement, $29 \%$ of the variances of self-efficiency, $26 \%$ of the variances of social self-efficiency, $41 \%$ of the variances of academic self-efficacy, and $28 \%$ of the variances of emotional self-efficiency in students. Accordingly, it can be concluded that theory of mind can predict academic achievement and self-efficiency in students with conduct disorder and it shows the relationship between these variables.
\end{abstract}

Keywords: Theory of mind abilities, academic achievement, self-efficiency, conduct disorder

\section{Introduction}

One of the problems that has effects on children and was widely considered by clinicians and psychologists, is conduct disorder. Conduct Disorder is a sustainable collection of behaviors that forms over time and often "characterized by aggression and violate regarding the rights of others (Saduk \& Saduk, 2007; Rezaei, et al., 2011). Children and adolescents with this disorder insist in the refusal of the rules at home, school or community and are inconsistent in school and disobey from the orders of authorities, and have many destructive behaviors. These students are impulsive, have poor judgment and they take risk in dangerous and incorrect occasions. They don't think about the consequences of their actions and always fail, they aren't responsible for their bad behaviors and aren't sensitive about the feelings, thoughts and needs of other people (Janksmy et al., 2000). Unlike many childhood problems that decreases with aging, anti-social behaviors with aging, are established; approximately 2- $7 \%$ of the entire community are affected by conduct disorder (Levinson et al., 2004). Conduct disorder cause many interpersonal problems among people due to having disruptive and reckless behaviors. Many factors may be involved in causing these symptoms which can also affect people's self-efficiency. Self-efficacy is defined as judgments about what one thinks, not what someone has done (Abolghasemi \& Narimani, 2005). Bandura, in his book titled "foundations of thought and social behavior suggests that people usually have a system of self-efficiency which is effective in controlling their thoughts, feelings and actions. This system includes a structure which brings about to some extent stability in human behavior. In other words it's the 
amount of people's ability to control their performances and environmental impacts (Bandura, 2001). The most important motivational variable relating to achievement goals from the perspective of researchers is self-efficacy beliefs (Liem et al., 2008). Factors such as self-efficiency beliefs and goals have an important role in understanding self-regulation and motivational processes in people (Seo, Barrett, \& Bartunek, 2004). It causes to the formation of deep processing and stability in doing homework (Finny, Pieper, \& Barron, 2004; Vanyperen, Elliot, \& Anseel, 2009).

Academic achievement is a growing curve which goes higher everyday by learning new things and it's the result of active mental processes that includes understanding the significant correlation between new information and prior knowledge of the learner (Aminabadi, 2011). Learning achievement means the amount of academic learning of individuals which was measured by different course exams such as dictation and mathematics (Anderson, 2002). Studies have shown that specific learning and self-efficiency difficulties are in close relationship with theory of mind (Jomepoor et al., 2015). Theory of mind is a vast structure that forms the foundation of social interaction in human. All people often during their natural growth and until age four, acquire the ability of distinguishing their mental states such as beliefs, desires, intentions and emotions towards others. Of course, in these abilities some changes occur in the growth process and part of these changes are related to cognitive growth (the cognitive abilities are done during the growing age of children and in aging time) and the other part relates to the experiences of children (which is formed in interaction with others) (Yazdi, 2012). Theory of mind is mental states, beliefs, intentions, hopes, prays and knowledge of self and others and it also refers to understanding the fact that other's beliefs and intentions are different from the beliefs and intentions of us. Having a theory of mind allows one to consider thoughts, wishes and intentions of other people and be able to predict or describe them and understand their intentions (Hayes et al, 2008). Studies have shown that theory of mind is relevant with self-understanding (Nejati et al., 2012; Beta et al., 2003), self-regulation and problem-solving skills (Sperling et al., 2009). On the other hand research results have shown that, aggressive children in theory of mind tasks act weaker than normal people. This study seeks to answer the question that: can theory of mind predict self-efficiency and academic achievement of students with conduct disorder in Ardabil?

\section{Methodology, Community and Method of Sampling}

This study is correlational, and academic achievement and self-efficiency are criterion variables and theory of mind was considered as the predictor variable. The number of students have been reported 28137 people. The study population consisted all students with conduct disorder in first grade of high school (secondary levels of 7 , $8,9)$ in Ardabil, in 2015. Multi-stage cluster sampling method was used. For this purpose, four schools were selected from regions 1 and 2 of Ardabil, following that 3 classes from each school and 32 person from each class were selected, the total of participants were 384 person. This number of sample size was selected based on Morgan's sampling table and more behavioral disorder questionnaires by Rutter form B, was placed at the disposal of teachers. After answering, people with conduct disorder were diagnosed and 60 people were selected as a sample group. Minimum of 25 people is ideal for correlational research (Delavar, 2006). This number of sample size was selected to enhance external validity and generalizability with more confident.

The following tools were used for data collection:

1) Self-Efficiency Questionnaire for Kids and adolescents: This questionnaire was prepared by Morris (2001) to assess self-efficiency in children and adolescents in social, educational and emotional aspects, and it includes 23 articles and three sub-tests. Social self-efficiency sub-test includes 8 first articles (questions 1 to 8 ) and it measures the ability to communicate with peers, determination and achieving to social norms. Academic self-efficiency subtest includes second 8 articles (questions 9 to 16), and it measures sense of empowerment in the management of learning behaviors, mastering the curriculum and proof expectations in academic achievement. Emotional self-efficacy sub-test includes the last 7 articles (questions 17 to 23) and it measures individuals' sense of ability in facing with and controlling negative emotions. Reliability of this test is good and its internal consistency is 0.80 . Factor analysis, shows three-factor structure in three areas of social, academic and emotional aspects (Morris, 2001) and its validity is based on appropriate and acceptable content and context validity. Reliability of three factors was reported 0.70 , reliability of social self-efficacy was 0.78 , reliability of academic self-efficacy was 0.87 , and for emotional self-efficacy it was reported 0.80 (Morris, 2001; quoted by Ardalan \& Hossein, 2011).

2) Hopi's theory of mind test: In this study to evaluate children's theory of mind, theory of mind questionnaire by Hopi will be used. This questionnaire was made in 1995, and it contains 12 stories regarding pretense, white lies, exaggeration, persuasion, forgetting, appearance, conscience, jokes, innuendo, misunderstanding, speech format and agitation of the opposition. This questionnaire for the first time in Iran was used by Razavieh et al. (1385). 
Arefi has reported validity coefficient and reliability of the questionnaire desirable (validity coefficient is 0.89 and reliability is 0.98 ). This test performed individually and scoring was on the basis that score zero is rewarded to errors subject to the reality of story or the presented condition of mind in the story. Score one is awarded to the answers which don't refer to the state of mind clearly but they considered the reality of story and score two is rewarded to answers which consider the story and refer to the state of mind clearly (Samadi, 2013).

3) Rutter's behavioral disorder questionnaire form B: Rutter' questionnaire form B, includes 26 phrases. The teacher in each of the 26 phrase chooses one of the phrase from "not true" to "absolutely right". Scores for responding to 26 phrases, will have a maximum of 52 score, and is considered as the distinction criterion. The time required for completing this questionnaire will be about 7 minutes. In a study by Abolqasemi (1383) this questionnaire was conducted on 60 ordinary students and who had problems. Reliability coefficient in making half and Cronbach's alpha were reported in this questionnaire respectively, 0.83 and 0.91 . Pearson's correlation coefficients showed that, there is a significant relationship between Rutter's questionnaire and questionnaire of behavioral problems by Shahim et al. The $t$ test results showed a significant difference between mean scores of normal children and who have problems in questionnaire by Rutter (Narimani \& Abolghasemi, 2006).

4) Academic achievement: In this study for investigating academic achievement of students, their mean score in the first term exams (January) was used.

\section{Procedure}

In this research, data were gathered by field study (data collection through questionnaire) and library method (collecting theoretical subjects), respectively. For data collection in questionnaire, the necessary licenses were obtained. By the use of multi-stage clustering sample method 4 schools were selected in Ardebil from regions 1 and 2, then 3 class from each school and 32 person from each class were selected, the total of participants were 384 person. This number of sample size was selected based on Morgan's sampling table. Then Rutter's behavioral disorder questionnaire form B was placed at the disposal of teachers and then 60 people who were diagnosed with conduct disorder, were selected as the sample group. After determining the sample group, self-efficacy and theory of mind questionnaires were put at the disposal of the people, and then first innings average was received and after answering questions, the gathered data were analyzed. To analyze the data, descriptive statistics such as frequency distribution table, mean and standard deviation to describe the data were used. To examine the hypothesis, Pearson correlation coefficient was used and Regression analysis was used to evaluate the research question and the results are reported in the following tables.

\section{Results}

Total respondents of the study were 60 people, (33.38 percent were female and 66.61 percent were male). And $30 \%$ of students aged 13 years, $33.38 \%$ aged 14 , and $66.31 \%$ aged 15 . The results also showed that 35 percent of students were in the first year of high school (secondary level of 7), $33.33 \%$ of students were in junior high school (secondary level of 8 ) and $31.66 \%$ of them were of junior high school (secondary level of 9) who were enrolled in the study and have responded to the mentioned questionnaire. The results of data analysis is reported in the following tables.

In this study, data analysis was done both by descriptive (mean and standard deviation) and inferential (Pearson correlation coefficient test and regression analysis) methods. The gathered results is reported below.

Table 1. The mean and standard deviation of scores related to self-efficiency, academic achievement and theory of mind

\begin{tabular}{lll}
\hline Variable & Mean & Standard Deviation \\
\hline Self-efficiency & 87.03 & 9.43 \\
Social self-efficiency & 24.16 & 5.32 \\
Academic self-efficiency & 21.11 & 3.29 \\
Emotional self-efficiency & 22.03 & 3.50 \\
Academic Achievement & 17.14 & 1.01 \\
Theory of mind & 30.48 & 7.73 \\
\hline
\end{tabular}

Results in Table 1 shows the mean and SD for self-efficiency was obtained 87.03 and 9.43, respectively. For social self-efficiency it was 24.16 and 5.32, for academic self-efficiency was 21.11 and 3.29 , for emotional self-efficiency was 22.03 and 3.50, for academic achievement was 17.14 and 1.01 and for theory of mind it was 
reported 30.48 and 7.73 , respectively.

Table 2. Correlation coefficient of theory of mind with self-efficiency and academic achievement

\begin{tabular}{lll}
\cline { 2 - 3 } Variable & Statistics & Theory of mind \\
\cline { 2 - 3 } Academic Achievement & correlation coefficient & 0.31 \\
& Significance level & 0.01 \\
Social self-efficiency & correlation coefficient & 0.27 \\
& Significance level & 0.03 \\
Academic self-efficiency & correlation coefficient & 0.25 \\
& Significance level & 0.04 \\
& correlation coefficient & 0.27 \\
Emotional self-efficiency & Significance level & 0.03 \\
& correlation coefficient & 0.30 \\
& Significance level & 0.01 \\
\hline
\end{tabular}

Note. $*(\mathrm{p}<0.05) * * \overline{(\mathrm{p}<0.01)}$

According to Table 2, Pearson correlation coefficient shows in the significant level of 0.05 and confidence coefficient of 0.95 . So, there is a significant relationship between theory of mind with academic achievement $(\mathrm{r}=0.31)$, Self-efficiency $(\mathrm{r}=0.27)$, Social self-efficiency $(\mathrm{r}=0.25)$, academic self-efficiency $(\mathrm{r}=0.27)$, and emotional self-efficiency $(\mathrm{r}=0.30)$. $(\mathrm{p}<0.05)$.

Table 3. Multivariate regression analysis results related to theory of mind in predicting academic achievement

\begin{tabular}{|c|c|c|c|c|c|}
\hline Model & Ss & Df & Ms & $\mathrm{F}$ & $\mathrm{P}$ \\
\hline Regression & 9.28 & 1 & 9.28 & 10.29 & 0.002 \\
\hline Remained & 52.27 & 58 & 0.90 & & \\
\hline \multirow[t]{2}{*}{ Total } & 61.55 & 59 & & & \\
\hline & R Rs & ARS & & & \\
\hline Predicator variables & & & Non-standardized & $\begin{array}{l}\text { standardized } \\
\text { coefficients }\end{array}$ & $\begin{array}{l}\text { T Sig } \\
\text { coefficients }\end{array}$ \\
\hline constant & & & $\mathrm{B} \mathrm{Se}$ & Beta & \\
\hline Ability of theory of & & & 15.640 .52 & - & 29.560 .000 \\
\hline Mind & 0.380 .15 & 0.13 & 0.050 .01 & 0.38 & 3.200 .002 \\
\hline
\end{tabular}

To determine the effect of theory of mind as a predictive variable and academic achievement as criterion variable, they were analyzed in the regression equation. As shown in Table (3), the amount of observed F is significant $(p<0.002)$ and $15 \%$ of the variances in academic achievement is explained by the theory of mind. According to Beta values $(\beta=0.38)$, theory of mind can predict significantly changes on the student's academic achievement.

Table 4. Multivariate regression analysis results related to theory of mind in predicting self-efficiency

\begin{tabular}{llllll}
\hline Model & Ss & Df & Ms & F & P \\
\hline Regression & 499.99 & 1 & 499.16 & 5.52 & 0.02 \\
Remained & 5241.56 & 58 & 90.37 & & \\
Total & 5740.73 & 59 & & & \\
& R Rs & ARS & & & \\
Predicator variables & & & Non-standardized & standardized & T Sig \\
& & & & coefficients & coefficients \\
\hline
\end{tabular}




\begin{tabular}{llllll}
\hline constant & & & B Se & Beta & \\
Ability of theory of & & & 75115.30 & - & 14.170 .000 \\
Mind & 0.280 .08 & 0.07 & 0.390 .16 & 0.29 & 2.350 .02 \\
\hline
\end{tabular}

To determine the effect of theory of mind as a predictive variable and self-efficiency as criterion variable, they were analyzed in the regression equation. As shown in Table (4), the amount of observed F is significant $(\mathrm{p}<0.02)$ and $8 \%$ of the variances in self-efficiency is explained by the theory of mind. According to Beta values $(\beta=0.29)$, theory of mind can predict significantly changes on the student's self-efficiency.

Table 5. Multivariate regression analysis results related to theory of mind in predicting social self-efficiency

\begin{tabular}{llllll}
\hline Model & Ss & Df & Ms & F & P \\
\hline Regression & 120.14 & 1 & 120.14 & 4.49 & 0.03 \\
Remained & 1548.78 & 58 & 26.70 & & \\
Total & 1668.93 & 59 & & & \\
& & R Rs & ARS & & \\
Predicator variables & & & Non-standardized & standardized & T Sig \\
& & & & coefficients & coefficients \\
constant & & & B Se & Beta & \\
Ability of theory of & 18.18 & 2.88 & - & 6.31 & 0.000 \\
Mind & 0.260 .07 & 0.05 & 0.190 .09 & 0.26 & 2.120 .03 \\
\hline
\end{tabular}

To determine the effect of theory of mind as a predictive variable and social self-efficiency as criterion variable, they were analyzed in the regression equation. As shown in Table 5, the amount of observed $\mathrm{F}$ is significant $(p<0.03)$ and $7 \%$ of the variances in social self-efficiency is explained by the theory of mind. According to Beta values $(\beta=0.26)$, theory of mind can predict significantly changes on the student's social self-efficiency.

Table 6. Multivariate regression analysis results related to theory of mind in predicting academic self-efficiency

\begin{tabular}{llllll}
\hline Model & Ss & Df & Ms & F & P \\
\hline Regression & 94.41 & 1 & 94.41 & 12.10 & 0.001 \\
Remained & 452.43 & 58 & 7.80 & & \\
Total & 546.58 & 59 & & & \\
& R Rs & ARS & & & \\
Predicator variables & & & Non-standardized & standardized & T Sig \\
& & & & coefficients & coefficients \\
constant & & & B Se & Beta & \\
Ability of theory of & 15.78 & 1.55 & - & 10.13 & 0.000 \\
Mind & 0.470 .17 & 0.15 & 0.170 .04 & 0.41 & 3.470 .001 \\
\hline
\end{tabular}

To determine the effect of theory of mind as a predictive variable and academic self-efficiency as criterion variable, they were analyzed in the regression equation. As shown in Table (6), the amount of observed $\mathrm{F}$ is significant $(\mathrm{p}<0.001)$ and $17 \%$ of the variances in academic self-efficiency is explained by the theory of mind. According to Beta values $(\beta=0.41)$, theory of mind can predict significantly changes on the student's academic self-efficiency. 
Table 7. Multivariate regression analysis results related to theory of mind in predicting emotional self-efficiency

\begin{tabular}{llllll}
\hline Model & Ss & Df & Ms & F & P \\
\hline Regression & 65.93 & 1 & 65.93 & 5.17 & 0.02 \\
Remained & 739.71 & 58 & 12.75 & & \\
Total & 805.65 & 59 & & & \\
& R Rs & ARS & & & \\
Predicator variables & & & Non-standardized & standardized & T Sig \\
& & & & coefficients & coefficients \\
constant & & & B Se & Beta & \\
Ability of theory of & 17.44 & 1.99 & - & 8.76 & 0.000 \\
Mind & 0.280 .08 & 0.06 & 0.140 .06 & 0.28 & 2.270 .02 \\
\hline
\end{tabular}

To determine the effect of theory of mind as a predictive variable and emotional self-efficiency as criterion variable, they were analyzed in the regression equation. As shown in Table 7, the amount of observed $\mathrm{F}$ is significant $(\mathrm{p}<0.02)$ and $8 \%$ of the variances in emotional self-efficiency is explained by the theory of mind. According to Beta values $(\beta=0.28)$, theory of mind can predict significantly changes on the student's emotional self-efficiency.

\section{Discussion and Conclusion}

The obtained results in this study are consistent with results in studies by Jomehpoor et al. (2015), Ali Akbari et al. (2013), Perner et al. (2002), Beta et al. (2003), Petnik (2008), Aylin et al. (2011), and Serna et al. (2014). Childhood and adolescence are the most important and most critical periods in the formation of personality and neglecting them will result in irremediable consequences because the foundation of tomorrow's society are today's children. In a society with less attention to children and adolescents, more and more social problems, abnormal children and delinquency can be observed. According to importance of children, it is noteworthy to consider their problems and fix them. One of the problems afflicting children and was widely considered by clinicians and psychologists, is conduct disorder. Conduct disorder has always attracted the attention of experts in different fields. On the one hand, this is perhaps due to the complexity and diversity of the causes of conduct disorder and on the other hand, variety of behavioral issues and their consequences in various fields could be important. Conduct disorder is a set of consistent behaviors that forms with the passage of time and is identified with symptoms such as cruelty to animals and people, destruction of properties, deceit, deception, lying, stealing, violating to the rights of others. Such problems will create serious problems for patients, families and communities (Boris \& Dalton, 2004; Hill, 2002). The aim of this study was to determine the relationship between theory of mind ability and academic achievement and self-efficiency of students with conduct disorder in Ardabil.

The first hypothesis of this study was: theory of mind ability has a relationship with academic achievement of students with conduct disorder in Ardabil. To verify this hypothesis the Pearson correlation coefficient test was used. The results showed that, there is a positive and significant relationship between theory of mind ability and academic achievement of students $(\mathrm{p}<0.05)$. The obtained results in this study are consistent with the results in studies by Jomehpoor et al. (2015), Petnik (2008), Aylin et al. (2011), and Serna et al. (2014). Theory of mind makes people enable to make relations between external mental status (protests, gestures, signs, etc.) and the inner states of mind (beliefs, feelings, intentions, etc.). And regarding this ability they will be able to predict the behavior of others in different social situations. Theory of mind or the ability to identify emotions, intentions and thoughts of others can be considered as one of the most important skills in a series called social intelligence skills (Goopink \& Meltezof, 1997; quoted by Mohammad, 2014). Social perception component is the ability to decode mental status of others by the use of visible and accessible information and social cognition component is the ability of receiving and inferring to the mental state of others in order to predict their behaviors (Wang et al., 2010). Theory of mind is a prerequisite for understanding the social environment, and it's needed for involving in competitive social behaviors. This ability helps students in the classroom and in relationship with teachers and classmates to communicate effectively and useful and they will be able to understand and learn easily the presented subjects by teacher. So, when this ability is stronger in students, they can be more successful and they will have better academic achievement. 
The second hypothesis of this study was: theory of mind ability has a relationship with self-efficiency (social, academic and emotional) of students with conduct disorder in Ardabil. To verify this hypothesis the Pearson correlation coefficient test was used. The results showed that there is a positive and significant relationship between theory of mind ability and self-efficiency (social, academic and emotional) of students $(\mathrm{p}<0.05)$. The obtained results in this study are consistent with the results in studies by Kakojoibari (2012), Perner et al. (2002), Beta et al. (2003) and Sperling et al. (2009). Self-efficiency is the "judge of people on their ability to organize and implement a series of actions to achieve specified types of operations" (Shahraray, 2007). Self-efficiency means personal conviction and based on that a person can do some behaviors to achieve the desired result. Self-efficiency can be referred to the idea that the person can dominate a situation and produce positive outcomes. Bandura believed that, self-efficiency has a powerful influence on behavior (Bandura, 2001). Self-efficiency is a person's conviction and according that a person can successfully execute the necessary behaviors to produce the desired results and also it reflects the overall confidence of a person about his or her ability to control and dominating over the environmental requests (Dadfar, 2011). Self-efficiency is applied regarding the judgments of people about their abilities for completing designed levels of performance (Moradi \& Taj, 2007). Meanwhile, theory of mind ability causes people act better about social situations and mental states of oneself and others and also about individual or general allocation of themselves, and it will increase their abilities to recognize their abilities and their function, so they will have higher levels of self-efficiency. In general, mental states involve a wide range of intentions, hopes, fears, expectations, desires, ideas, and etc and three of these states are the main factors for interpretation and prediction of the people's behaviors (Kazdin, 2000). So it increases the ability of perception in a person in relation with self-efficiency and self-understanding. This is an explanation for the relationship between self-efficiency and theory of mind.

Research question was: can theory of mind predict self-efficiency and academic achievement of students with conduct disorder in Ardabil? Regression analysis was used to examine this question and results showed that theory of mind can predict significantly about $38 \%$ of the variances of academic achievement, $29 \%$ of the variances of self-efficiency, $26 \%$ of the variances of social self-efficiency, $41 \%$ of the variances of academic self-efficiency and $28 \%$ of the variances of emotional self-efficiency in students. Theory of mind is defined as the power of the human mind to imagine himself and others modes (Leslie, 1988). Schafer (2000) considers theory of mind for distinguishing "public self" and "private self" that implies the acquisition of theory of mind, and understanding the fact that people have mental states, beliefs, desires and intentions, which often guide their behaviors. Hepeh (1994) believes that the theory of mind helps individuals regarding the feelings, beliefs, and intentions of others, and offers a good explanation and description of their behaviors. So people who have higher levels of theory of mind, can perceive mental abilities and aspirations of other people and this can improve academic performance and self-efficiency of people. Researches on their way encounter with some limitations. This study was also associated with some limitations such as limitation to choose statistical sample in Ardebil, limited sample of high school students with conduct disorder (secondary 7, 8,9), lack of access and allowance for researchers to control variables related to the individuals (family variables, environment, school, etc.) and lack of control for comorbidity of other mental disorders in the study group. It is recommended to the interested researchers in this field that theory of mind, academic achievement and self-efficiency of students will be investigated with considering other psychological variables. It is suggested that in future research confounding variables such as family and cultural factors will be controlled in groups. According to the positive relationship between theory of mind and emotional, social and academic self-efficiency and academic achievement in students, it is recommended to school counselors and psychologists to use educational methods based on promotion of theory of mind to enhance self-efficiency and academic achievement of students with conduct disorder. It is suggested that training should be offered some in service trainings for teachers regarding conduct disorder, theory of mind, self-efficiency and academic achievement. Also some programs should be designed to increase knowledge of parents and it would be helpful for students with conduct disorder. At the end we should thank all those who helped us to complete this research.

\section{References}

Amin, Y. A. (2004). Transmission of "theory of mind" in children. Journal of Education and Psychology, 5(1), 41-49.

Aminabadi, Z. (2011). Comparing the effectiveness of two methods of metacognitive strategies and teaching by the use of software to improve cognitive functions and academic progress of students with dyslexia (Master's Thesis in Psychology). University of Mohaghegh in Ardebil.

Anderson, C. A., \& Bushman, B. J. (2002). Human aggression. Annual Review Psychology, 53(3), 27-51. 
Ardalan, E., \& Hossein, C. M. (2011). Predicting academic adjustment based on communicational skills through self-efficacy beliefs. Journal of Educational Psychology, 17, 28-1.

Arjmand, M., Rezaei, F., Foghani, J. N. (Trans.). (2011). Clinical Psychiatry (2nd Eds.). Arjmand Publications, pp. 436-439.

Aylin, L., \& Rosario, T. (2011). Impact of executive functions and the theory of mind on academic achievement. A longitudinal study, Neurosis. Conference Abstract: XI International Conference on Cognitive Neuroscience (ICON XI).270. 263

Bandura, A. (2001). Social cognitive theory: Annul review of psychology. Palo Alto, CA: Annul review s. Belmont, CA: Wadworth.

Beate, S., Christian, H., \& Claudia, T. (2003). The self and action in theory of mind research. Jurnal of Consciousness and Cognition, 12, 777-782.

Dadfar, S. (2011). The effectiveness of social problem solving on self-control, self-efficiency and impulsivity of students with addiction potential (Master's thesis in clinical psychology). Ardebil Islamic Azad University.

Delavar, A. (2006). Research methods in the humanities. Tehran: Roshd Publications.

Finny, S., Pieper, S., \& Barron, K. (2004). Examining the psychometric properties of the achievement goal questionnaire in a general academic context. Journal of Educational and Psychological Measurement, 64(2), 365-382.

Hayes, S. C., Barnes, H. D., \& Roche, B. (2008). Relations frame theory. Journal A Post- Developmental Disorders, 31, 589-599.

Hill, J. (2002). Biological, psychological and social process in the conduct disorders. Journal of Child Psychology \& Psychiatry, 43(1), 133-164.

Jomehpoor, M., Mohammadpoor, H., \& Dastjerdi, R. (2015). Compare theory of mind development in children with and without specific learning difficulties. Journal of Exceptional Education, 15(4), 23-13.

Jongsmy, A., Deterson, M., \& Mclnnis, W. (2000). The child psychotherapy treatment planner. John Wiley Sons/ Inc.

Lewinsohn, P., Rohde, P., \& Farrington, D. (2000). The OADP-CDS: A Brief screener for adolescent conduct disorder. Child and Adolescent Psychiatry, 39, 888-889.

Liem, A. D., Lau, S., \& Nie, Y. (2008). The role of self-efficacy, task value, and achievement goals in predicting learning strategies, task disengagement, peer relationship, and achievement outcome. Journal of Contemporary Educational Psychology, 33(2), 486-512.

Moradi, T. (2013). Investigating the relationship of general self-efficiency and scientific view in academic achievement of pre-university students in majors physics, biology and chemistry (Master's thesis, General Psychology). Tabriz University.

Narimani, M., \& Abolghasemi, A. (2006). Psychological tests. Ardebil: Baghe Rezvan Publications.

Nejati, V., Zabihzadeh, A., Nikfarjam, M. R., Pournaghdali, A., Naderi, Z., \& Tajmir, R. M. (2012). Self as a social cue: Evidence for reading mind from eyes test. Jurnal of Procedia - Social and Behavioral Sciences, $32,82-88$.

Perner, J, Lang, B., \& Kloo, D. (2002). Theory of mind and self-control: more than a common problem of inhibition. Child Dev, 73(3), 752-67.

Razavieh, A., Latifian, M., \& Arefi, M. (2006). The role of theory of mind and empathy on predicting obvious aggressive communicational behaviors and prosocial behaviors in students. Journal of Psychological Studies, 2(4), 25-38.

Samadi, \& Sahar (2013). Comparing ability of theory of mind and self-understanding in juvenile offenders of Ardabil city (Master's Thesis in Clinical Psychology). Islamic Azad University, Ardabil.

Seo, M., Barrett, L., \& Bartunek, J. M. (2004). The role of affective experience in work motivation. Journal of Academy of Management, 29, 423-439.

Serena, L., Marcella, C., \& Adriano, P. (2014). Long-term effect of theory of mind on school achievement: The role of sensitivity to criticism. European Journal of Developmental Psychology, 11(3), 305-318.

Shahraray, M. (2006). Theory of research and Applications (Johan, Pintrich, Artin, \& Shang, Trans., 2002). 
Tehran: Arjmand Publications.

Sperling, R. A., Walls, H., \& Hill, A. (2009). Early relationships among self-regulatory constructs: Theory of mind and preschool children's problem salving. Journal of Child Study, 30(4), 233-252.

Van Yperen, N. W., Elliot, A. J., \& Anseel, F. (2009). The influence of mastery avoidance goals on performance improvement. European Journal of Social Psychology, 39, 932-943.

Wang, Y. G., Wang, Y., Chen, S., Zhua, C., \& Wang, K. (2010). Theory of mind disability in major depression with or without psychotic symptoms: A componential view. Journal of Psychiatry Research, 161(2), 15361.

\section{Copyrights}

Copyright for this article is retained by the author(s), with first publication rights granted to the journal.

This is an open-access article distributed under the terms and conditions of the Creative Commons Attribution license (http://creativecommons.org/licenses/by/4.0/). 